\title{
Construction of an enzymatic route using a food-grade recombinant Bacillus subtilis for the production and purification of epilactose from lactose
}

\author{
Qiuming Chen, ${ }^{*}$ Weiwei He, ${ }^{*}$ Xin Yan, $†$ Tao Zhang, ${ }^{*}$ Bo Jiang, ${ }^{*} \ddagger$ Timo Stressler, $§$ Lutz Fischer, $§$ \\ and Wanmeng $\mathrm{Mu}^{*} \ddagger^{1}$ \\ *State Key Laboratory of Food Science and Technology, Jiangnan University, Wuxi 214122, China \\ †Department of Microbiology, College of Life Sciences, Key Laboratory for Microbiological Engineering of Agricultural Environment \\ of the Ministry of Agriculture, Nanjing Agricultural University, 6 Tongwei Road, Nanjing, Jiangsu 210095, China \\ fInternational Joint Laboratory on Food Safety, Jiangnan University, Wuxi 214122, China \\ §Institute of Food Science and Biotechnology, Department of Biotechnology and Enzyme Science, University of Hohenheim, Garbenstr. 25, \\ 70599 Stuttgart, Germany
}

\begin{abstract}
Lactose is a main by-product in the cheese industry. Many attempts have been made to convert the lactose to high value-added products, including epilactose. Epilactose is a valuable prebiotic and can be epimerized from lactose with cellobiose 2-epimerase (CEase). The objective of the present work was to construct a food-grade recombinant Bacillus subtilis that produces CEase from Thermoanaerobacterium saccharolyticum. The CEase was expressed in B. subtilis without antibiotic resistance genes. After fermentation, the maximum volumetric activity of the fermented broth was more than $7 \mathrm{U} / \mathrm{mL}$. The activity of the recombinant B. subtilis was increased by up to 3.7 fold after ethanol permeabilization. Then, $66.9 \pm 0.7 \mathrm{~g} / \mathrm{L}$ of epilactose was produced from $300 \mathrm{~g} / \mathrm{L}$ of whey powder solution in $1 \mathrm{~h}$ with $13.3 \mathrm{U} / \mathrm{mL}$ of permeabilized biocatalyst. In addition, an enzymatic route including degradation of the lactose, yeast fermentation, and cation exchange chromatography was described to further purify the produced epilactose from lactose. Finally, epilactose with a purity $>98 \%$ was produced from $300 \mathrm{~g} / \mathrm{L}$ of lactose with a yield of $24.0 \%$. In conclusion, neither antibiotics nor pathogenic bacteria were used throughout the epilactose production and purification procedure.
\end{abstract}

Key words: lactose, epilactose, cellobiose 2-epimerase, food-grade

\section{INTRODUCTION}

Cheese whey is usually considered a liquid by-product in the cheese industry ( $\mathrm{Mu}$ et al., 2013). As the main carbohydrate in cheese whey, lactose is produced

Received March 26, 2017.

Accepted October 31, 2017.

${ }^{1}$ Corresponding author: wmmu@jiangnan.edu.cn at a high and constant rate by the dairy industry every year. According to data from University of Wisconsin, the average annual production of condensed whey in the United States is over 50 million $\mathrm{kg}$ in the last $3 \mathrm{yr}$, and for dry whey the number is 420 million $\mathrm{kg}$ with the price of lower than $\$ 0.2 / \mathrm{kg}$ (University of Wisconsin, 2017). However, the presence of lactose at a concentration of 4.8 to $5.3 \%$ makes whey an environmental problem because of its high biochemical oxygen demand (Procentese et al., 2015). Although lactose removal is accompanied by its production process, the low price of the product reduces the value of this process. This fact would necessitate better uses of lactose or methods to enhance the added value of the product (Jin et al., 2016).

Biotechnologists have found enzymatic modifications to produce many valuable lactose derivatives, such as galactooligosaccharide produced with $\beta$-galactosidase (Rodriguez-Colinas et al., 2014), lactosucrose synthetized with levansucrase ( $\mathrm{Li}$ et al., 2015), and poly (3-hydroxybutyrate) fermented through poly(hydroxyalkanoate) (PHA)-producing bacteria (Berwig et al., 2016). Epilactose (4-O- $\beta$-Dgalactopyranosyl-D-mannose) is an epimer of lactose. This disaccharide is resistant to rat intestinal enzymes and beneficially changes the intestinal flora (Ito et al., 2008), which gives it better prebiotic properties than lactose (Watanabe et al., 2008). In addition, epilactose can considerably promote the calcium absorption in rat small intestines (Nishimukai et al., 2008; Suzuki et al., 2010) and possibly lower the risk of arteriosclerosis (Nishimukai et al., 2008).

Epilactose is difficult to chemically synthesized $(\mathrm{Mu}$ et al., 2013), but can be epimerized enzymatically from lactose without a co-substrate by cellobiose 2-epimerase (EC 5.1.3.11; CEase), which shows promising potential for industrial application. Cellobiose 2-epimerase is the only enzyme that exhibits epimerization activity 
toward disaccharides (Van Overtveldt et al., 2015). The CEase from Thermoanaerobacterium saccharolyticum JW/SL-YS485 is relatively thermostable and shows high epimerization activity toward lactose (Chen et al., 2015). This enzyme exhibits little isomerization activity other than CEase from Caldicellulosiruptor saccharolyticus (Park et al., 2011) and Dictyoglomus turgidum (Kim et al., 2012). All reported CEase were overexpressed in the Escherichia coli expression system, which features endotoxins on the cell membrane (Zobel et al., 2015) and often requires antibiotic resistance genes on the plasmid. Unlike E. coli, Bacillus subtilis is nonpathogenic and is classified as a generally recognized as safe (GRAS) strain by the US Food and Drug Administration. The D-alanine racemase gene on the chromosome of $B$. subtilis can be knocked out as an auxotrophic selective marker to avoid the usage of antibiotic. Moreover, Bacillus subtilis has been used in large-scale food fermentation for years and is more prolific than E. coli, which makes it a better and safer choice as a host microorganism in the food industry.

In contrast with enzyme immobilization, biocatalysts in the form of whole cells can avoid the loss of repeated uses and time-consuming purification steps. Besides, it is more convenient to concentrate the enzymes in cells than their free forms. After centrifugation, the whole cells can be freeze-dried for long-term storage; however, the reaction rates in whole cells are often limited by the permeability barrier of the cell envelope. Permeabilization was widely used to prepare whole-cell biocatalysts, such as yeast cells (Lee et al., 2004; Panesar et al., 2007) and gram-negative cells (Wang et al., 2015). To reduce the permeability of the recombinant Bacillus subtilis, ethanol permeabilization of cells was conducted to increase the use rate of the whole-cell biocatalyst. In the current study, we constructed a food-grade expression system using an antibiotic resistance gene-free plasmid and evaluated the productivity of epilactose from lactose with this recombinant organism.

\section{MATERIALS AND METHODS}

\section{Chemicals}

Epilactose and gel filtration chromatography standards were purchased from Sigma-Aldrich (St Louis, $\mathrm{MO}$ ). Cheese whey powder was purchased from Apple Foods Tech (Shanghai, China). Ethanol to permeabilize the cells was obtained from Feizhidao Food Ingredients Factory (Henan, China), and $\beta$-galactosidase (EC 3.2.1.23) from Bifidobacterium bifidum purchased from Sangon Biotech (Shanghai, China); both were foodgrade. The electrophoresis reagents were from Bio-Rad (Hercules, CA). Phusion HF DNA Polymerase was from
New England Biolabs (Beijing, China). The primers for PCR amplification and all other chemicals in this study were obtained from Sangon Biotech (Shanghai, China).

\section{Microorganisms and Shake Flask Fermentation}

The B. subtilis $1 \mathrm{~A} 751$ host strain, pET-Thsa-CE, p7S6, pTSC, and pUB-P43-DPE-dal plasmid (Chen et al., 2015; He et al., 2016) in this work were obtained from our laboratory. Escherichia coli DH5a competent cells were purchased from TaKaRa Biotechnology (Dalian, China). Luria-Bertani (LB) medium supplemented with $200 \mu \mathrm{g} / \mathrm{mL}$ of D-alanine was used to culture B. subtilis $1 \mathrm{~A} 751$ without the dal (D-alanine racemase) gene.

\section{Strategy for Cre/lox System Knockout of dal Gene}

The entire dal gene (GenBank no. CAB12271.1), along with expression regulatory signals, were knocked out using the Cre/lox system (Yan et al., 2008). A fusion of the linear DNA fragments was assembled using a PCR-based method (Shevchuk et al., 2004) with the following steps. The lox71-spc-lox66 cassette was amplified from the p7S6 vector by PCR using primer I and II. Two flanking homology regions ( $\sim 900 \mathrm{bp}$ each) of the $d a l$ gene were separately amplified with 2 pair of primers $\mathrm{P} 3 / \mathrm{P} 4$ and $\mathrm{P} 5 / \mathrm{P} 6$ (Table 1). Because primers $\mathrm{P} 1$ and $\mathrm{P} 2$ contain the corresponding reverse complementary sequences of adjacent fragments $\mathrm{P} 4$ and P5, respectively, these gel-purified DNA fragments can be simultaneously fused into one. The final product was used to realize the in-frame deletion of the dal gene of the $B$. subtilis host $1 \mathrm{~A} 751$ chromosome. Luria-Bertani agar supplemented with D-alanine and spectinomycin was used to select the transformants, whose dal chromosomal genes were replaced by lox71-spc-lox66 cassettes. The plasmid pTSC containing the Cre recombinase expression gene was then introduced into the verified true positive transformants. The lox71 and lox66 sites can be recombined into a double-mutant lox 72 site with Cre recombinase. The temperature-sensitive plasmid pTSC was then eliminated by heating up to $51^{\circ} \mathrm{C}$

\section{Construction of Antibiotic Resistance Gene-Free Plasmid}

An antibiotic resistance gene-free plasmid pUB-P43DPE-dal to produce D-psicose 3-epimerase (DPEase) fused with endogenous promoter P43 was previously constructed in our laboratory (He et al., 2016). The plasmid in our study was recombined based on pUBP43-DPE-dal. The method developed by You et al. (2012) without restriction enzymes and ligases was 
Table 1. Oligonucleotides used for construction of plasmids and DNA fragments ${ }^{1}$

\begin{tabular}{ll}
\hline Primer & Sequence $\left(5^{\prime}-3^{\prime}\right)$ \\
\hline P1 & TTACCTTCTCTCTTCTAAGTACCGTTCGTATAGCAT \\
P2 & CAAGCAAAGCTGTTTATCTACCGTTCGTATAATGT \\
P3 & TACAAAGCAAAAGCGAAAATGACCATC \\
P4 & ATGCTATACGAACGGTACTTAGAAGAGAGAAGGTAA \\
P5 & ACATTATACGAACGGTAGATAAAACAGCTTTGCTTG \\
P6 & CAGCTGATAGGATTCTTGCTCGCTTA \\
P7 & CATTATAGGTAAGAGAGGAATGTACACATGGAGAAAATAGTACATGAAAT \\
P8 & CTGTACGTTCCTTAAGGAATTCTTAGTGGTGGTGGTGGTGGTGACTCACTGTTTTTCACC \\
P9 & ATTTCATGTACTATTTTCTCCATGTGTACATTCCTCTCTTACCTATAATG \\
P10 & CACCACCACCACCACCACTAAGATTCCTTAAGGAACGTACAG \\
\hline
\end{tabular}

${ }^{1}$ The bold letters indicate the introduction of histidine tags. The underlined letters indicate the reverse complementary sequences of the corresponding primers.

used for the plasmid construction. The DPEase expression gene region was replaced by the sequence of CEase from T. saccharolyticum JW/SL-YS485 (NCBI accession number: AFK87331.1) in 4 steps. (1) The CEase gene was amplified from plasmid pET-Thsa-CE used in our previous study (Chen et al., 2015) by PCR with the primers P7/P8; P7 and P8 contain 23 and 22 bp reverse complementary sequences at the 3 '-terminus of primers P9 and P10 (underlined), respectively. A C-terminal 6 $\times$ His-tag fused with a stop codon (bold) was added to primer $\mathrm{P} 8$ to facilitate the subsequent purification. (2) The primers P9 and P10 were similarly designed to amplify the vector backbone (the linear fragment outside the DPEase expression gene region of pUBP43-DPE-dal). (3) The large DNA multimers of the PCR products in the previous 2 steps in tandem were formed via prolonged overlap extension PCE without primers (Zhang and Zhang, 2011). (4) The desired plasmid, pUB-P43-TsCE-dal, was obtained by directly transforming the prolonged overlap extension PCR products (DNA multimer) into B. subtilis 1A751 (dal ${ }^{-}$) competent cells.

\section{Segregational Stability}

The segregational stability of antibiotic resistance gene-free plasmid was determined according to the method described by Yu et al. (2012). One milliliter of LB medium in the absence of D-alanine was inoculated with a $1 \mathrm{~A} 751 / \mathrm{pUB}-\mathrm{P} 43$-TsCE-dal colony and incubated for $24 \mathrm{~h}$. This culture was used to inoculate into $1 \mathrm{~mL}$ of fresh LB at $1 \%$ inoculum, incubated for $24 \mathrm{~h}$, and inoculated into $1 \mathrm{~mL}$ of $\mathrm{LB}$ with D-alanine at $1 \%$ inoculum to begin the segregation stability test. The culture was subcultured in LB supplemented with D-alanine at $1 \%$ inoculum every $24 \mathrm{~h}$ to reach the identical cell density. The cultures at $72 \mathrm{~h}$ were diluted and plated on LB plates (containing $200 \mu \mathrm{g} / \mathrm{mL}$ of D-alanine; plate $\mathrm{D})$, and replica-plated on an LB plate (plate C). The numbers of colonies on each LB plate were counted as
$\mathrm{C}_{\mathrm{D}}$ and $\mathrm{C}_{\mathrm{C}}$, respectively. The segregational stability of the recombinant plasmid was expressed as the value of $\mathrm{C}_{\mathrm{C}} / \mathrm{C}_{\mathrm{D}}$

\section{Purification of the Recombinant Protein}

The histidine tag was used to facilitate the purification of the target protein. The recombinant cells were cultivated in 2-L flasks, which contained $100 \mathrm{~mL}$ of LB medium for $36 \mathrm{~h}$, and harvested by centrifugation at $6,000 \times g$ for $20 \mathrm{~min}$. The resuspended cells were disrupted with a Scientz-II D ultrasonic homogenizer (Scientz Biotechnology, Ningbo, China). The crude CEase obtained from the previous step was filtered and purified by $\mathrm{Ni}^{2+}$ affinity chromatography from GE Healthcare (Uppsala, Sweden). All purification steps were implemented according to the manufacturer's protocol (Instruction 71-5001-87 AE, http://wolfson.huji .ac.il/purification/PDF/Tag_Protein_Purification/Ni -NTA/AMERSHAM_Chelating_Instruction.pdf; GE Healthcare) at $4^{\circ} \mathrm{C}$. The purified protein was dialyzed against $50 \mathrm{mM}$ sodium phosphate buffer $(\mathrm{pH}$ 7.0) for $8 \mathrm{~h}$.

\section{Molecular Mass Determination}

The subunit molecular masses of the crude and purified enzyme solutions were examined by SDS-PAGE. A $5 \%$ (wt/vol) stacking gel and a $12 \%$ (wt/vol) separating gel were used to perform SDS-PAGE. The gel was then stained and destained with Coomassie Blue G250 (Sangon Biotech, Shanghai, China) and a mixture of acetic acid, methanol, and water (10:10:80 vol/vol/vol, respectively).

An HPLC system (Agilent Technologies, Santa Clara, CA) was used to determine the native molecular mass of the purified recombinant enzyme. The separation was performed in a TSK gel G3000 SWXL (Tosoh Bioscience LLC, Tokyo, Japan) column with $0.1 \mathrm{~mol} / \mathrm{L}$ phosphate buffer ( $\mathrm{pH}$ 6.8), which contained $0.1 \mathrm{~mol} / \mathrm{L}$ 
of $\mathrm{Na}_{2} \mathrm{SO}_{4}$, and $0.05 \% \mathrm{NaN}_{3}$ at a flow rate of $1 \mathrm{~mL} / \mathrm{min}$. The samples and protein standards $(669,443,200,150$, 66 , and $29 \mathrm{kDa}$ ) were detected at $280 \mathrm{~nm}$ using a UV detector.

\section{Enzyme Assay}

The activity of recombinant CEase was determined based on the whole-cell reactions. One milliliter of the aqueous reaction mixture contained $200 \mathrm{~m} M$ lactose, $50 \mathrm{~m} M$ sodium phosphate buffer ( $\mathrm{pH} 7.0$ ), and $200 \mu \mathrm{L}$ of resuspended recombinant cell solution. The reaction mixture was incubated at $60^{\circ} \mathrm{C}$ for $15 \mathrm{~min}$, and $\mathrm{HCl}$ was subsequently added with a final concentration of $250 \mathrm{mM}$. The activities of the cells permeabilized by 20 to $70 \%$ ( vol/vol) ethanol were measured based on 15 min of reactions using lactose as substrate. One unit of CEase activity was defined as the amount of enzyme that produced $1 \mu \mathrm{mol}$ of epilactose per minute at $\mathrm{pH} 7.0$ and $60^{\circ} \mathrm{C}$. Epilactose produced during the enzymatic reactions was detected using an HPLC system (Waters 2695, Milford, MA) equipped with a Shodex VG-50 4E $(4.6 \mathrm{~mm}$ id $\times 250 \mathrm{~mm}, 5 \mu \mathrm{m}$; particle size, Shodex, Tokyo, Japan). The mobile phase was a mixture of methanol, acetonitrile, and water (75: 20: 5, $\mathrm{vol} / \mathrm{vol} / \mathrm{vol}$ ) with a flow rate of $1.0 \mathrm{~mL} / \mathrm{min}$ at $40^{\circ} \mathrm{C}$. The compounds with approximately equal or longer retention time than that of the trisaccharide standard were added together as galactooligosaccharides (GOS), including trisaccharides, tetrasaccharides, and pentasaccharides. The amount $(<1 \%)$ of disaccharides generated by the transgalactosylation reaction was ignored.

\section{Bioconversion of Epilactose from Lactose}

After $36 \mathrm{~h}$ of incubation, the recombinant B. subtilis was harvested by centrifugation at $6,000 \times g, 4^{\circ} \mathrm{C}, 20$ min. It was then resuspended to a final concentration of $150 \mathrm{~g}$ of wet cells/L by $50 \%$ ( $\mathrm{vol} / \mathrm{vol}$ ) ethanol solution with agitation for $20 \mathrm{~min}$ at $25^{\circ} \mathrm{C}$, and washed twice with sodium phosphate buffer $(\mathrm{pH}$ 7.0) to remove the residues of raw materials in the fermentation media. The recombinant cells suspension was adjusted to 18 $\mathrm{U} / \mathrm{mL}$ of the original volumetric activity. Then, $200 \mathrm{~mL}$ of biocatalyst was permeabilized and added to $800 \mathrm{~mL}$ of $375 \mathrm{~g} / \mathrm{L}$ of lactose in a sodium phosphate buffer $(\mathrm{pH}$ 7.0) for a final lactose concentration of $300 \mathrm{~g} / \mathrm{L}$. The yields of the epilactose in this section were detected by sampling following the method of enzyme assay. When equilibrium was reached, the enzymatic reaction was stopped by immersing the vessels in a boiling water bath for $10 \mathrm{~min}$. After centrifugation $\left(8,000 \times g, 4^{\circ} \mathrm{C}\right.$, $20 \mathrm{~min}$ ), the supernatant of $375 \mathrm{~g} / \mathrm{L}$ of cheese whey powder solution ( $\mathrm{pH}$ 7.0) was filtered and used for bioconversion in the described manner.

\section{Purification of Epilactose}

The total sugar concentration of the reaction mixture was adjusted to $100 \mathrm{~g} / \mathrm{L}$ with sodium phosphate buffer ( $\mathrm{pH}$ 7.0). Then, $\beta$-galactosidase was added to a final concentration of $25 \mathrm{U} / \mathrm{mL}(250 \mathrm{U} / \mathrm{g}$ of initial lactose). One unit of $\beta$-galactosidase can hydrolyze 1 $\mu$ mol o-nitrophenyl- $\beta$-D-galactopyranoside per minute at $25^{\circ} \mathrm{C}$ and $\mathrm{pH} 7.5$. The mixture was incubated with shaking at $25^{\circ} \mathrm{C}$ for $12 \mathrm{~h}$. After the hydrolysis reaction, fresh baker's yeast Saccharomyces cerevisiae (Angel Yeast Co. Ltd., Yichang, China) was used with the addition of $15 \mathrm{~g}$ (wet weight) of yeast per $100 \mathrm{~g}$ of sugar to remove the monosaccharides. The fermentation mixture was stirred at $28^{\circ} \mathrm{C}$ for $12 \mathrm{~h}$ in an aerobic flask. Finally, the mixture was centrifuged $\left(6,000 \times g, 4^{\circ} \mathrm{C}\right.$, $20 \mathrm{~min}$ ) and the GOS and remaining monosaccharides in the supernatant were removed with a preparative cation-exchange chromatograph equipped with a preparative column $(1.6 \mathrm{~cm} \times 1 \mathrm{~m})$ packed with Na-type cation-exchange resin DTF-01 (Jiangsu Suqing Water Treatment Engineering Group Co. Ltd., Wuxi, China). The mobile phase was deionized water with a flow rate of $1 \mathrm{~mL} / \mathrm{min}$ at $60^{\circ} \mathrm{C}$. The injection volume was $5 \mathrm{~mL}$.

\section{RESULTS}

\section{Selection of the dal Gene Deficiency Strains}

The scheme to knockout the structural dal gene from the $B$. subtilis $1 \mathrm{~A} 751$ chromosome was presented in detail in a previous report from our laboratory (He et al., 2016). The dal gene deficiency variant B. subtilis $1 \mathrm{~A} 751$ $\left(d a l^{-}\right)$was obtained on the LB agar with D-alanine and confirmed by PCR. This deficiency variant strains cannot grow on the general culture medium without the addition of D-alanine.

\section{Construction of Food-Grade Recombinant Strains}

Plasmid pUB-P43-TsCE-dal, which derives from pUB110, can be used as an expression vector to produce recombinant proteins in B. subtilis. This plasmid lacks an antibiotic resistance gene (kanamycin and bleomycin) unlike pUB110. A CEase expression gene with 2 tandem promoters ( $H p a I I$ and P43) and an inframe $6 \times$ His-tag sequence was substituted for the Mob gene in pUB-P43-TsCE-dal. The flow diagram to construct the food-grade plasmid pUB-P43-TsCE-dal is illustrated in Figure 1. The PCR multimer product 

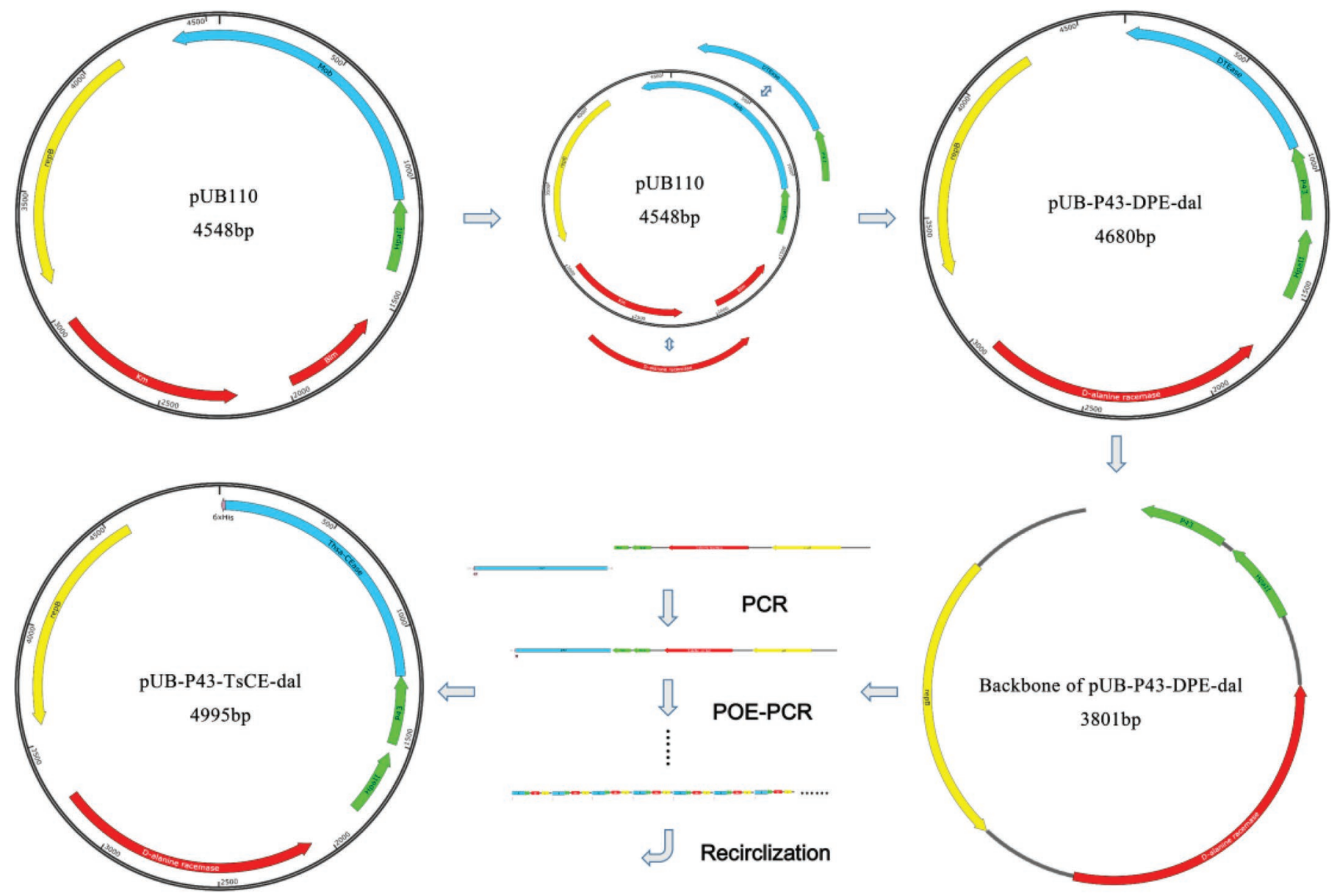

Figure 1. Flow diagram for constructing the food-grade plasmid pUB-P43-TsCE-dal. The plasmid pUB-P43-DPE-dal, featuring 2 tandem promoters HpaII and P43, was constructed from the original vector pUB110. The D-psicose 3-epimerase expression gene was inserted into the Mob gene region and 2 antibiotic resistance genes (kanamycin and bleomycin) of pUB110 were replaced by the D-alanine racemase gene. Plasmid pUB-P43-TsCE-dal derived from pUB-P43-DPE-dal was constructed by a general, restriction enzyme-free and ligase-free method, as described in Materials and Methods. POE = prolonged overlap extension. Color version available online.

was directly transformed into B. subtilis $1 \mathrm{~A} 751$ (dal ${ }^{-}$) competent cells, yielding plasmid pUB-P43-TsCE-dal. The recombinant B. subtilis 1A751/pUB-P43-TsCE-dal screened by LB agar without D-alanine was simultaneously obtained. The $\mathrm{C}_{\mathrm{C}} / \mathrm{C}_{\mathrm{D}}$ ratio of plasmid pUB-P43TsCE-dal was higher than $99.5 \pm 0.2 \%$ after the culture in the presence of D-alanine for $72 \mathrm{~h}$.

\section{Fermentation of the Recombinant Strain}

A single colony of 1A751/ pUB-P43-TsCE-dal was picked for the LB medium. After $12 \mathrm{~h}$ of cultivation at $37^{\circ} \mathrm{C}$, the precultures were inoculated at a $1: 50$ dilution into $300 \mathrm{~mL}$ of $\mathrm{LB}$ medium in a 3 -L flask, and incubated at $37^{\circ} \mathrm{C}$ on a rotary shaker at $200 \mathrm{rpm}$. Samples $(1 \mathrm{~mL})$ were taken regularly to monitor cell growth at $600 \mathrm{~nm}$. It took approximately $30 \mathrm{~h}$ for the culture to grow to the highest optical density at $600 \mathrm{~nm}$. The maximum concentration of the wet cells reached 16.5 $\pm 1.8 \mathrm{~g}(3.3 \pm 0.3 \mathrm{~g}$ for dry cells $)$ per liter of culture medium. The enzymatic activity curve of the whole cell of 1A751/ pUB-P43-TsCE-dal, which lagged behind the cell growth curve, reached a plateau after $48 \mathrm{~h}$ of incubation (Figure 2). The maximum volumetric activity of the fermentation broth measured by HPLC was more than $7 \mathrm{U} / \mathrm{mL}$. The crude enzyme was obtained by sonication and, thus, the target proteins' expression percentage after $48 \mathrm{~h}$ was then determined to be $37.1 \pm 4.7 \%$ based on the activity of the permeabilized medium divided by specific activity.

\section{Purification of Recombinant Protein}

Purified enzyme was produced by 1-step nickelaffinity chromatography to electrophoretic homogeneity with a single band at approximately $47 \mathrm{kDa}$ using 


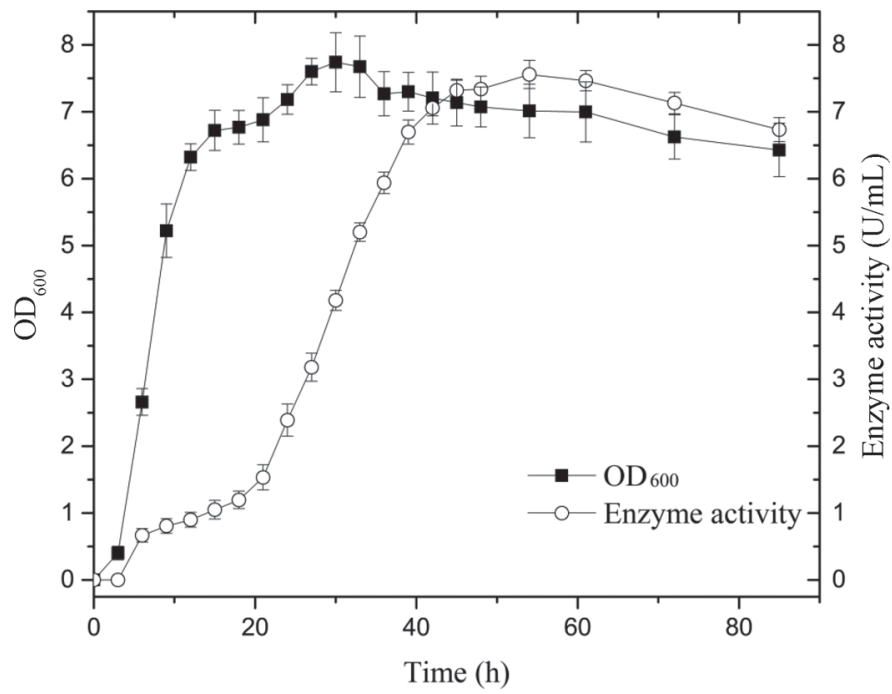

Figure 2. Enzyme activity curve and growth curve of the recombinant strain. The enzyme units per milliliter fermentation broth $(\bigcirc)$ and optical density at $600 \mathrm{~nm}\left(\mathrm{OD}_{600} ; \mathbf{\square}\right)$ were used to describe the enzyme activity curve and growth curve. The values in the figure are the average of 3 independent measurements and are given as the mean $\pm \mathrm{SD}$.

SDS-PAGE (Figure 3A), which was consistent with the molecular mass obtained using a gel filtration analysis (Figure 3B). These analyses indicate that the native CEase overexpressed by $1 \mathrm{~A} 751 / \mathrm{pUB}-\mathrm{P} 43-\mathrm{TsCE}-$ dal existed as a $47-\mathrm{kDa}$ monomer and the recombinant CEase was identical in size to CEase from the E. coli expression system (Chen et al., 2015).

\section{Production of Epilactose by Whole-Cell Recombinant $B$. subtilis and Ethanol Treatment}

The cell sediment that harbors CEase can be vacuum freeze-dried; thus, $1 \mathrm{~L}$ of 48 -h fermentation broth $(\sim 7,200 \mathrm{U}$ of total activity) was dried to $2.81 \mathrm{~g}$ of dry cells. The activity of dry cells was determined to be $3,250 \mathrm{U} / \mathrm{g}$, which was an increase of $27 \%$ compared with the activity of wet cells. The freezing and thawing, which contribute to the permeability of cells for the substrates, may cause this improvement (Chen, 2007). To investigate the effect of permeabilization, the activity of the cells preprocessed by ethanol permeabilization was measured based on the 15 min of reaction (Figure 4). The enzyme activity steadily increased when the ethanol concentration increased from 20 (vol/ vol) to $50 \%$ ( $\mathrm{vol} / \mathrm{vol}$ ), and a decrease in activity was observed with further increase in concentration. All the reaction mixtures had nearly identical final epilactose yields $(\sim 29 \%)$.

The laboratory-scale production reaction by the whole-cell biocatalyst of permeabilized recombinant $B$. subtilis was conducted in a shake flask. First, $300 \mathrm{~g} / \mathrm{L}$ of lactose was converted into $88.5 \pm 0.6 \mathrm{~g} / \mathrm{L}$ of epilactose $(29.5 \pm 0.2 \%$ in yield $)$ with an original activity of $3.6 \mathrm{U} / \mathrm{mL}$ of the whole cells (raised to $13.3 \mathrm{U} / \mathrm{mL}$ by permeabilization) at $\mathrm{pH} 7.0$ and $60^{\circ} \mathrm{C}$ for $1.5 \mathrm{~h}$ (Figure $5)$. The in situ production of epilactose from lactose was performed with supernatant of cheese whey powder solution. The reaction mixture containing $228.2 \pm$ $1.2 \mathrm{~g} / \mathrm{L}$ of lactose $(76 \%$ of total weight of cheese whey

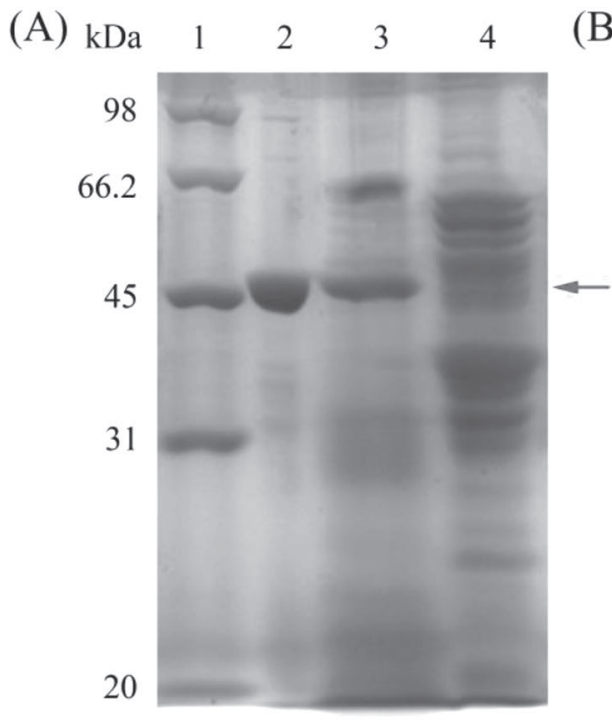

(B)

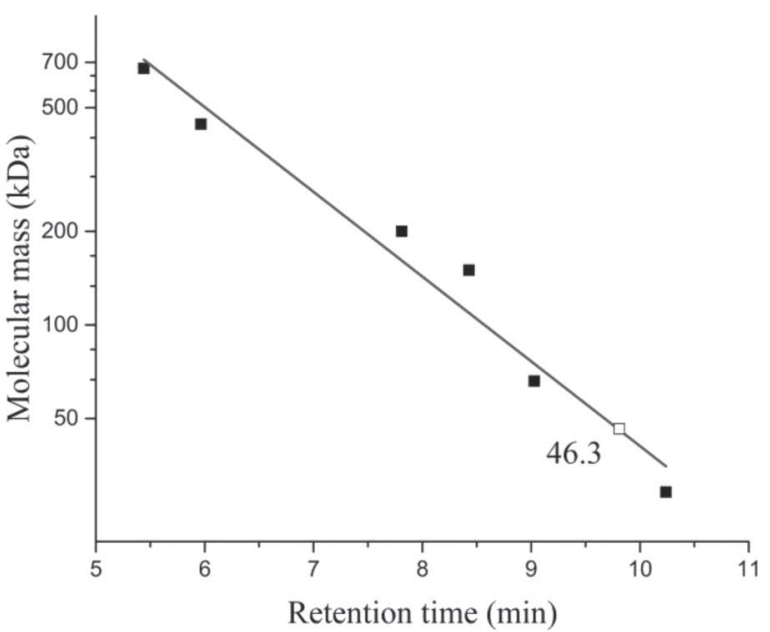

Figure 3. Estimation of the molecular mass of cellobiose 2-epimerase from Thermoanaerobacterium saccharolyticum by SDS-PAGE and gel filtration. (A) SDS-PAGE analysis of Thsa-CE. Lanes: 1, molecular mass marker proteins. 2, purified enzyme. 3, crude enzyme from Bacillus subtilis pUB-P43-TsCE-dal. 4, B. subtilis 1A751 (negative control). (B) Gel filtration chromatography of Thsa-CE. 
powder) was incubated in condition identical to those mentioned previously. The existence of the other components in whey did not strongly influence the activity of the whole-cell biocatalyst. As the concentration of the lactose in cheese whey powder solution was less than the previous reaction, $66.9 \pm 0.7 \mathrm{~g} / \mathrm{L}$ of epilactose was produced in $1 \mathrm{~h}$ with $13.3 \mathrm{U} / \mathrm{mL}$ of permeabilized biocatalyst (Figure 5). Both the sources of the lactose and the permeabilization process did not change the reaction equilibrium.

\section{Purification of Epilactose from the Reaction Mixture}

A food-grade strategy to remove of the residual lactose in the reaction mixtures is described in this work. Figure 6 demonstrates the flow diagram to purify epilactose. First, lactose was selectively degraded with $\beta$-galactosidase that hydrolyzed lactose into galactose and glucose. The second step is optional, where yeast fermentation was conducted to remove the generated monosaccharides. The last step is preparative cationexchange chromatography. Most monosaccharides and GOS were successfully separated from lactose and epilactose (Table 2); $87 \%$ of the epilactose applied to the column was finally collected with purity $>98 \%$, which indicates that $24.0 \mathrm{~g}$ of epilactose can be obtained from $100 \mathrm{~g}$ of lactose.

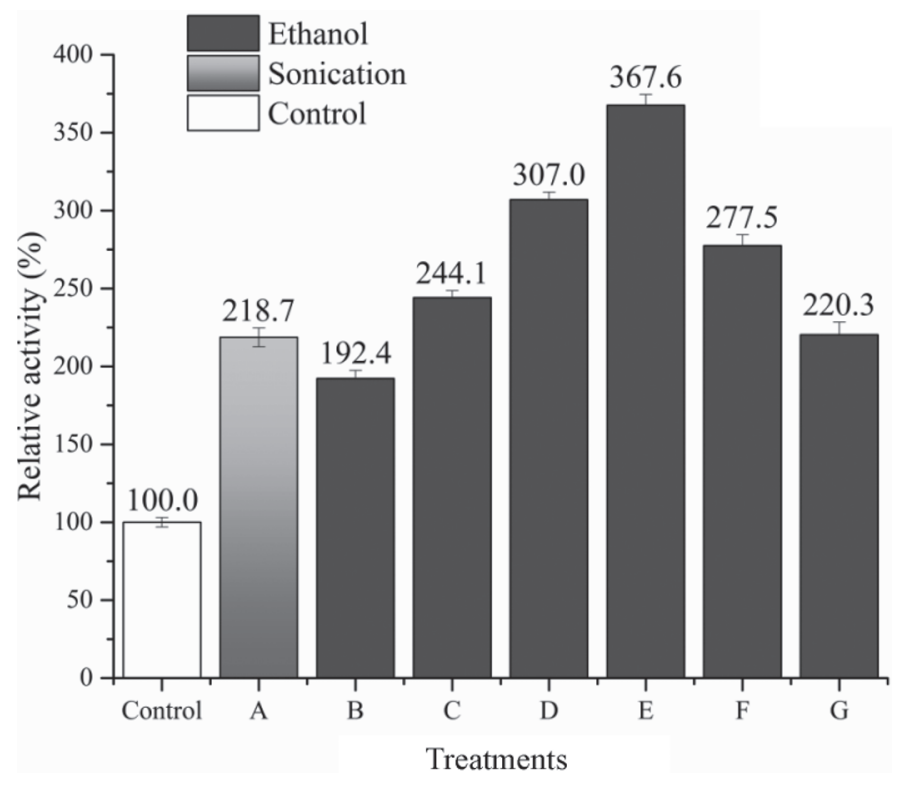

Figure 4. Effect of sonication or permeabilization on the activity of the recombinant cells. The initial activity without treatment was taken as $100 \%$. A represents activity of the cells disrupted by sonication; B, C, D, E, F, and G represent activities of the permeabilized cells using $20,30,40,50,60$, and $70 \%$ ( $\mathrm{vol} / \mathrm{vol}$ ) ethanol, respectively. The values are the means of 3 replications $\pm \mathrm{SD}$.

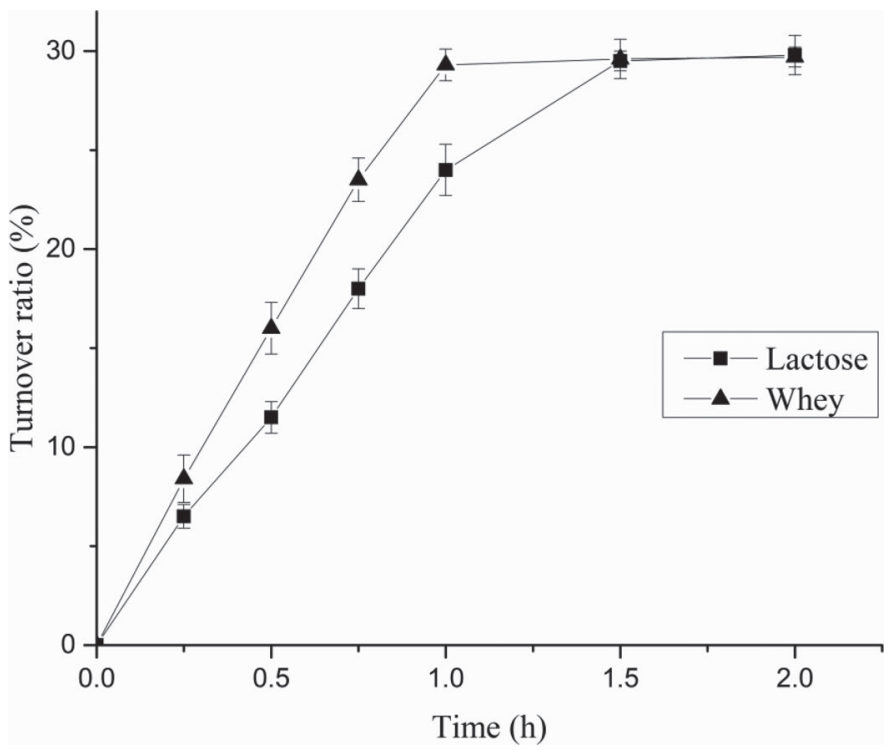

Figure 5. Time course of the enzymatic lactose conversion. The enzymatic reaction was performed from $300 \mathrm{~g} / \mathrm{L}$ of lactose $(\mathbf{\square})$ and $300 \mathrm{~g} / \mathrm{L}$ of cheese-whey powder solution $(\mathbf{\Lambda})$ at $\mathrm{pH} 7.0$ and $60^{\circ} \mathrm{C}$. The values are the means of 3 replications $\pm \mathrm{SD}$.

\section{DISCUSSION}

D-Alanine is involved in the growth of the cell wall, which makes it an essential component that is not found in common media. The deficiency of the dal gene provides a strong selectable marker, without which D-alanine cannot be converted from L-alanine. As a result, B. subtilis $1 \mathrm{~A} 751\left(\right.$ dal $\left.^{-}\right)$is a good host strain for a food-grade expression system. Antibiotic resistance genes and antibiotics were not required for this recombinant cell to maintain replicative plasmids. Therefore, the fermentation product of recombinant cells can be directly used in the bioconversion of epilactose from lactose, which eliminates the removal procedure of antibiotics and hidden dangers for food security.

The plasmid segregational stability is expressed as the percentage or probability of the host retaining the plasmid per generation, which is an essential issue in industrial application. The segregational stability of the recombinant plasmid pUB-P43-TsCE-dal is as stable as pUB-P43-DPE-dal (He et al., 2016). The plasmid pUB-P43-DPE-dal can be used as a backbone to construct other expression vectors with only 4 steps and 4 primers. The PCR amplifications were conducted using Phusion polymerase because of its high fidelity and high speed (You et al., 2012). This flexible, low-cost, and time-saving method requires no consideration of restriction sites and is independent of restriction enzymes and ligases, which can be used as a tool in other food-grade expressions for different heterologous genes. 

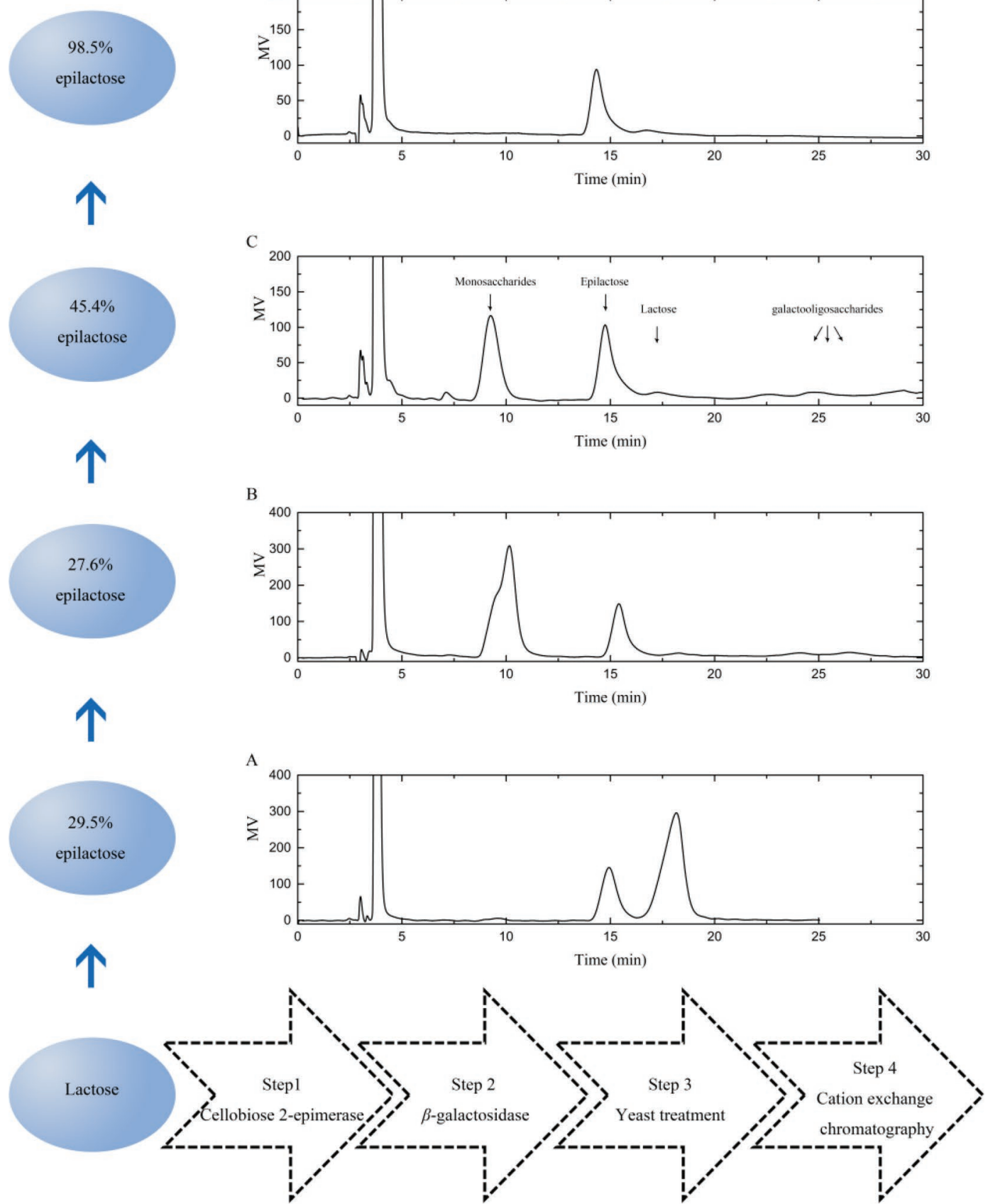

Figure 6. Strategy to purify epilactose from the reaction mixture. A, B, C, and D show the HPLC profiles of the products of steps 1 , 2, 3, and 4 , respectively. Color version available online.

Table 2. Purity and yield of epilactose after each purification step

\begin{tabular}{lccc}
\hline Step & Concentration of epilactose $(\mathrm{g} / \mathrm{L})$ & Purity $(\%)$ & Yield $(\%)$ \\
\hline Epimerization & $88.5 \pm 0.6$ & 29.5 & 29.5 \\
Dilution & $29.5 \pm 0.2$ & 29.5 & 29.5 \\
Degradation of the lactose & $27.6 \pm 0.2$ & 27.6 & 27.6 \\
Yeast fermentation & $27.5 \pm 0.2$ & 45.4 & 27.5 \\
Cation exchange chromatography & $24.0 \pm 0.1$ & 98.5 & 24.0 \\
\hline
\end{tabular}

${ }^{1}$ The concentration values are the means of 3 replications \pm SD. 
This new pUB110-based expression vector has 2 advantages. (1) The plasmid pUB110 has a high copy number, greater than $40 \mathrm{U} /$ chromosome, replicating by a rolling-circle mechanism, and the plasmid pUBP43-TsCE-dal with the rep proteins gene of pUB110 retains the expression level of the target protein. (2) A strong promoter $\mathrm{P} 43$ was added immediately behind the original promoter HpaII, which constructs a double promoter plasmid. The dual-promoter system is often used for better protein expression. For instance, the Tr-tac promoter was constructed using different regulation mechanisms for different expression levels at different conditions (Huang et al., 2016). In this case, the dual promoter HpaII-P43 using the same regulation mechanism was built to further improve the expression level. Therefore, the recombinant strains 1 A751/pUB$\mathrm{P} 43-\mathrm{TsCE}$-dal accumulate heterologous proteins with a distinct band on SDS-PAGE.

This laboratory-scale fermentation was conducted in the widely used LB medium. In our previous work, the recombinant strains containing the DPEase gene were cultivated using a super-rich medium (tryptone $25 \mathrm{~g} / \mathrm{L}$, yeast extract $20 \mathrm{~g} / \mathrm{L}, \mathrm{K}_{2} \mathrm{HPO}_{4} 3 \mathrm{~g} / \mathrm{L}$, glucose $30 \mathrm{~g} / \mathrm{L}$ ) as the fermentation medium. The maximum enzyme activity appeared earlier (13 h of fermentation time) and the maximum optical density value was slightly higher than that of $1 \mathrm{~A} 751 / \mathrm{pUB}-\mathrm{P} 43-\mathrm{TsCE}-\mathrm{dal}$ in the current work (He et al., 2016). Thus, a super-rich medium is recommended to satisfy the nutritional requirements of the recombinant strains and significantly shorten the fermentation time. However, super-rich media might be too costly to produce epilactose for industrial production. Nevertheless, the fermentation product of 1A751/ pUB-P43-TsCE-dal with the LB medium exhibited excellent catalytic ability compared with the $E$. coli expression system (Chen et al., 2015).

Further studies were performed to increase the utilization rate of the biocatalyst. The recombinant cells were permeabilized to help substrates and products hurdle the barrier that is the cell envelope. Compared with untreated cells, up to a 3.7 -fold increase in epilactose production activity was obtained for treated cells. An identical concentration of epilactose can be obtained with a smaller volume of permeabilized $B$. subtilis than with the untreated biocatalyst. Surprisingly, the permeabilized cells performed better (1.68 fold) than the cells that were disrupted by sonication. This difference may be because of the protective effects of permeabilized cells or presence of other proteins. It was suggested that a better stabilization of enzyme will be performed in the presence of other cellular proteins due to in vitro macromolecular crowding effect (Myung and Zhang, 2013). By comparison, the synthesis activ- ity of lactulose from lactose catalyzed with yeast cells containing $\beta$-D-galactosidase were increased by up to 1.5 fold after ethanol permeabilization (Panesar et al., 2007). In another study, the use of $40 \%$ (vol/vol) ethanol to permeabilize E. coli cells that harbored CEase from Caldicellulosiruptor saccharolyticus increased the production of lactulose by just 1.1 fold (Wang et al., 2015), indicating that the treatment with ethanol to enhance the permeability of the gram-negative cell envelope for lactose and its derivatives was not efficient compared with that of gram-positive bacterium Bacillus subtilis. This interesting phenomenon is seemingly quite different from the case of the Gram staining reaction, where the gram-positive microorganisms with a relatively thick cell wall are impermeable and resist the decolorization of $96 \%$ (vol/vol) ethanol (Popescu and Doyle, 1996). Because other processes, such as toluene permeabilization, freezing and thawing, and electropermeabilization, are either unsuitable for the food industry or time-consuming, treatment with ethanol may be the best method for this gram-positive whole-cell biocatalyst.

The activity of the recombinant enzyme and productivity of epilactose were nearly identical to the lactose in the buffer matrix, which indicates that the whole-cell biocatalyst worked well in the presence of various components of whey powders. Such enzymes can reduce the lactose content of milk or whey and provide prebiotics, which provide benefits to the well-being and health of humans. For example, CEase from Caldicellulosiruptor saccharolyticus was directly used in milk to produce epilactose (Krewinkel et al., 2014, 2015) or lactulose (Rentschler et al., 2015) in previous studies.

For purification of epilactose, lactose was selectively degraded with $\beta$-galactosidase. Apart from the lactose hydrolysis, $\beta$-galactosidase also catalyzed a transgalactosylation reaction, yielding a mixture of GOS $(5.3 \%$, wt/wt), disaccharides (28.2\%, wt/wt), and monosaccharides $(66.5 \%, \mathrm{wt} / \mathrm{wt})$. The transgalactosylation reaction was weakened by diluting the total concentration of sugar in the mixtures. More importantly, $\beta$-galactosidase preferentially hydrolyzes lactose other than epilactose, resulting in epilactose accounting for $98.2 \%$ of the disaccharides. This supplementary evidence shows that epilactose is a nondigestible food ingredient.

Although the yeast treatment has been widely used to purify GOS (Goulas et al., 2007), difructose dianhydride III, and kojibiose, the result that $41.3 \%$ of monosaccharides remained after purification was not ideal. The reason may be that the galactose and mannose in the mixture cannot be completely metabolized (Goulas et al., 2007). Nevertheless, removal of the monosaccha- 
rides before the implementation of liquid chromatography is still recommended for better performance.

A similar method with 4 steps was used to purify epilactose by Saburi et al. (2010), where monosaccharides were successfully fermented into glycerol after yeast treatment. However, the selectivity of hydrolysis by Bacillus circulans $\beta$-galactosidase and purity of product (91.1\%) were relatively low (Saburi et al., 2010). Kuschel et al. (2016) developed a non-food-grade method to produce epilactose; under the best conditions, the final epilactose purity was $99 \%$ with a total yield of $51 \%$.

\section{CONCLUSIONS}

An efficient epilactose-producing B. subtilis strain was developed based on an antibiotic resistance genefree plasmid. These recombinant cells can be directly used as a whole-cell biocatalyst in industrial production without unsafe factors and complex purification steps. In our results, $66.9 \pm 0.7 \mathrm{~g} / \mathrm{L}$ of epilactose was produced from $300 \mathrm{~g} / \mathrm{L}$ of whey powder solution for $1 \mathrm{~h}$ with $13.3 \mathrm{U} / \mathrm{mL}$ of permeabilized biocatalyst. Further purification of epilactose from lactose was described in this work. We found that epilactose with purity $>98 \%$ was produced from $300 \mathrm{~g} / \mathrm{L}$ of lactose solution with a yield of $24.0 \%$, which may direct a new enzymatic route for the production of epilactose.

\section{ACKNOWLEDGMENTS}

This work was supported by the Support Project of Jiangsu Province, China (No. 2015-SWYY-009), Postgraduate Research \& Practice Innovation Program of Jiangsu Provence, China (KYCX17_1406), and the project of outstanding scientific and technological innovation group of Jiangsu Province, China (Jing Wu).

\section{REFERENCES}

Berwig, K. H., C. Baldasso, and A. Dettmer. 2016. Production and characterization of poly(3-hydroxybutyrate) generated by Alcaligenes latus using lactose and whey after acid protein precipitation process. Bioresour. Technol. 218:31-37.

Chen, Q., W. Zhang, T. Zhang, B. Jiang, and W. Mu. 2015. Characterization of an epilactose-producing cellobiose 2-epimerase from Thermoanaerobacterium saccharolyticum. J. Mol. Catal., B Enzym. 116:39-44.

Chen, R. R. 2007. Permeability issues in whole-cell bioprocesses and cellular membrane engineering. Appl. Microbiol. Biotechnol. 74:730-738.

Goulas, A., G. Tzortzis, and G. R. Gibson. 2007. Development of a process for the production and purification of $\alpha$ - and $\beta$-galactooligosaccharides from Bifidobacterium bifidum NCIMB 41171. Int. Dairy J. 17:648-656.

He, W., W. Mu, B. Jiang, X. Yan, and T. Zhang. 2016. Construction of a food grade recombinant Bacillus subtilis based on replicative plasmids with an auxotrophic marker for biotransformation of Dfructose to D-allulose. J. Agric. Food Chem. 64:3243-3250.

Huang, R., H. Chen, C. Zhong, J. E. Kim, and Y. H. Zhang. 2016. High-throughput screening of coenzyme preference change of thermophilic 6-phosphogluconate dehydrogenase from $\operatorname{NADP}(+)$ to NAD. Sci. Rep. 6:32644.

Ito, S., H. Taguchi, S. Hamada, S. Kawauchi, H. Ito, T. Senoura, J. Watanabe, M. Nishimukai, S. Ito, and H. Matsui. 2008. Enzymatic properties of cellobiose 2-epimerase from Ruminococcus albus and the synthesis of rare oligosaccharides by the enzyme. Appl. Microbiol. Biotechnol. 79:433-441.

Jin, Y., A. Parashar, B. Mason, and D. C. Bressler. 2016. Simultaneous hydrolysis and co-fermentation of whey lactose with wheat for ethanol production. Bioresour. Technol. 221:616-624.

Kim, J. E., Y. S. Kim, L. W. Kang, and D. K. Oh. 2012. Characterization of a recombinant cellobiose 2-epimerase from Dictyoglomus turgidum that epimerizes and isomerizes $\beta$-1,4- and $\alpha$-1,4-glucooligosaccharides. Biotechnol. Lett. 34:2061-2068.

Krewinkel, M., M. Gosch, E. Rentschler, and L. Fischer. 2014. Epilactose production by 2 cellobiose 2-epimerases in natural milk. J. Dairy Sci. 97:155-161.

Krewinkel, M., J. Kaiser, M. Merz, E. Rentschler, B. Kuschel, J. Hinrichs, and L. Fischer. 2015. Novel cellobiose 2-epimerases for the production of epilactose from milk ultrafiltrate containing lactose. J. Dairy Sci. 98:3665-3678.

Kuschel, B., F. Riemer, D. Pfost, J. Conrad, C. Losch, W. Claaßen, U. Beifuß, J. Weiss, W. Mu, B. Jiang, T. Stressler, and L. Fischer. 2016. Large-scale purification of epilactose using a semi-preparative HPLC system. Eur. Food Res. Technol. 243:391-402.

Lee, Y. J., C. S. Kim, and D. K. Oh. 2004. Lactulose production by $\beta$-galactosidase in permeabilized cells of Kluyveromyces lactis. Appl. Microbiol. Biotechnol. 64:787-793.

Li, W., S. H. Yu, T. Zhang, B. Jiang, T. Stressler, L. Fischer, and W. M. Mu. 2015. Efficient biosynthesis of lactosucrose from sucrose and lactose by the purified recombinant levansucrase from Leuconostoc mesenteroides B-512 FMC. J. Agric. Food Chem. 63:9755-9763.

Mu, W., Q. Li, C. Fan, C. Zhou, and B. Jiang. 2013. Recent advances on physiological functions and biotechnological production of epilactose. Appl. Microbiol. Biotechnol. 97:1821-1827.

Myung, S., and Y.-H. P. Zhang. 2013. Non-complexed four cascade enzyme mixture: Simple purification and synergetic co-stabilization. PLoS One 8:e61500.

Nishimukai, M., J. Watanabe, H. Taguchi, T. Senoura, S. Hamada, H. Matsui, T. Yamamoto, J. Wasaki, H. Hara, and S. Ito. 2008. Effects of epilactose on calcium absorption and serum lipid metabolism in rats. J. Agric. Food Chem. 56:10340-10345.

Panesar, R., P. S. Panesar, R. S. Singh, J. F. Kennedy, and M. B. Bera. 2007. Production of lactose-hydrolyzed milk using ethanol permeabilized yeast cells. Food Chem. 101:786-790.

Park, C. S., J. E. Kim, J. G. Choi, and D. K. Oh. 2011. Characterization of a recombinant cellobiose 2-epimerase from Caldicellulosiruptor saccharolyticus and its application in the production of mannose from glucose. Appl. Microbiol. Biotechnol. 92:1187-1196.

Popescu, A., and R. J. Doyle. 1996. The Gram stain after more than a century. Biotech. Histochem. 71:145-151.

Procentese, A., F. Raganati, G. Olivieri, M. E. Russo, P. Salatino, and A. Marzocchella. 2015. Continuous lactose fermentation by Clostridium acetobutylicum - Assessment of solventogenic kinetics. Bioresour. Technol. 180:330-337.

Rentschler, E., K. Schuh, M. Krewinkel, C. Baur, W. Claassen, S. Meyer, B. Kuschel, T. Stressler, and L. Fischer. 2015. Enzymatic production of lactulose and epilactose in milk. J. Dairy Sci. 98:6767-6775.

Rodriguez-Colinas, B., L. Fernandez-Arrojo, A. O. Ballesteros, and F. J. Plou. 2014. Galactooligosaccharides formation during enzymatic hydrolysis of lactose: Towards a prebiotic-enriched milk. Food Chem. 145:388-394.

Saburi, W., T. Yamamoto, H. Taguchi, S. Hamada, and H. Matsui. 2010. Practical preparation of epilactose produced with cellobi- 
ose 2-epimerase from Ruminococcus albus NE1. Biosci. Biotechnol. Biochem. 74:1736-1737.

Shevchuk, N. A., A. V. Bryksin, Y. A. Nusinovich, F. C. Cabello, M. Sutherland, and S. Ladisch. 2004. Construction of long DNA molecules using long PCR-based fusion of several fragments simultaneously. Nucleic Acids Res. 32:e19.

Suzuki, T., M. Nishimukai, M. Takechi, H. Taguchi, S. Hamada, A. Yokota, S. Ito, H. Hara, and H. Matsui. 2010. The nondigestible disaccharide epilactose increases paracellular Ca absorption via rho-associated kinase- and myosin light chain kinase-dependent mechanisms in rat small intestines. J. Agric. Food Chem. 58:1927-1932.

University of Wisconsin. 2017. Dairy marketing and risk management program. Accessed Sep. 30, 2017. http://future.aae.wisc.edu/tab/ production.html\#10001.

Van Overtveldt, S., T. Verhaeghe, H. J. Joosten, T. van den Bergh, K. Beerens, and T. Desmet. 2015. A structural classification of carbohydrate epimerases: From mechanistic insights to practical applications. Biotechnol. Adv. 33:1814-1828.

Wang, M., R. Yang, X. Hua, Q. Shen, W. Zhang, and W. Zhao. 2015. Lactulose production from lactose by recombinant cellobiose 2-epimerase in permeabilised Escherichia coli cells. Int. J. Food Sci. Technol. 50:1625-1631.
Watanabe, J., M. Nishimukai, H. Taguchi, T. Senoura, S. Hamada, H. Matsui, T. Yamamoto, J. Wasaki, H. Hara, and S. Ito. 2008. Prebiotic properties of epilactose. J. Dairy Sci. 91:4518-4526.

Yan, X., H. J. Yu, Q. Hong, and S. P. Li. 2008. Cre/lox system and PCR-based genome engineering in Bacillus subtilis. Appl. Environ. Microbiol. 74:5556-5562.

You, C., X. Z. Zhang, and Y. H. Zhang. 2012. Simple cloning via direct transformation of PCR product (DNA Multimer) to Escherichia coli and Bacillus subtilis. Appl. Environ. Microbiol. 78:1593-1595.

Yu, M., Y. Du, W. Jiang, W. L. Chang, S. T. Yang, and I. C. Tang. 2012. Effects of different replicons in conjugative plasmids on transformation efficiency, plasmid stability, gene expression and N-butanol biosynthesis in Clostridium tyrobutyricum. Appl. Microbiol. Biotechnol. 93:881-889.

Zhang, X. Z., and Y. Zhang. 2011. Simple, fast and high-efficiency transformation system for directed evolution of cellulase in Bacillus subtilis. Microb. Biotechnol. 4:98-105.

Zobel, S., J. Kumpfmuller, R. D. Sussmuth, and T. Schweder. 2015. Bacillus subtilis as heterologous host for the secretory production of the non-ribosomal cyclodepsipeptide enniatin. Appl. Microbiol. Biotechnol. 99:681-691. 